\title{
Implicit Cognitive Distortions and Sexual Offending
}

\author{
Stephen Mihailides, ${ }^{1,4}$ Grant J. Devilly, ${ }^{2}$ and Tony Ward $^{3}$
}

This work develops and tests the semantic-motivation hypothesis of sexual offenders' implicit cognitions. This hypothesis posits that sexual offenders' cognitive distortions emerge at the interface between implicit motivation and cognition. The semantic-motivation hypothesis is used to guide the development of $3 \mathrm{im}$ plicit association tests (IATs). These IATs were used to test for the existence of 3 expected child sexual offender implicit cognitive distortions in child sexual offenders ("children as sexual beings," "uncontrollability of sexuality," and "sexual entitlement-bias"). Results showed that child sexual offenders had larger IAT effects than did mainstream offenders and male and female nonoffenders for the "children as sexual beings" and the "uncontrollability of sexuality" implicit theories. Child sexual offenders also had a larger IAT effect than male and female nonoffenders for the "sexual entitlement-bias" implicit theory. Implications for the semantic-motivation hypothesis are discussed.

KEY WORDS: Implicit Association Test; semantic-motivation; sexual offending; cognitive distortions.

\section{INTRODUCTION}

Theories that explicate the motivations underlying sexual offending, in general, suffer from a lack of supporting empirical evidence. Ward and Keenan (1999) and Ward (2000) have posited a theory of sexual offender implicit cognitive distortions that may inform motivational models of sexual offending, but until now has not been empirically evaluated. The theory also makes a number of tacit

\footnotetext{
${ }^{1}$ Department of Psychology, University of Melbourne, Victoria, Australia.

${ }^{2}$ Center for Neuropsychology, Swinburne University, Hawthorn, Victoria, Australia.

${ }^{3}$ School of Psychology, Victoria University of Wellington, Wellington, New Zealand.

${ }^{4}$ To whom correspondence should be addressed either Dr Stephen Mihailides, Department of Psychology, University of Melbourne, Victoria 3010, Australia; e-mail: spmihail@unimelb.edu.au or Grant Devilly, Centre for Neuropsychology, Swinburne University, P.O. Box 218, Hawthorn, Victoria 3122, Australia; e-mail: gdevilly@swin.edu.au.
} 
assumptions that require clarification. As a belief-desire account of sexual functioning, there is a silent hierarchy of motivations implied in the Ward (2000) theory. The "belief" elements are well covered (e.g., see Ward's "schema-as-theory" - the "theory theory") and provide structural foundations for implicit theories. To date, there has been far less development of the motivational components implied by Ward's theory. Thus, Ward's theory is primarily a statement about knowledge elements and in regards to how sexual offenders see themselves, the world, and their future. In particular, Ward's (2000) statements about sexual offenders' beliefs are summarized in five well-known sexual offender cognitive distortions: children as sexual beings, uncontrollability of sexuality, sexual entitlement bias, the nature of harm, and dangerous world implicit theories. The focus of this work relates to the first three of the five implicit theories.

Furthermore, Ward's (2000) theory of sexual offender implicit cognitions does not comment upon the micro-cognitive aspects underlying distorted thinking. Instead, this theory is a macro-level framework with less detail embedded in the model regarding micro-cognitive factors. That is, missing in the theory are the actual building blocks that are involved in the structures and processes of the implicit self. This article provides experimental data suggestive of these building blocks.

This work clarifies and further develops Ward's (2000) work by mapping motivational constructs onto implicit (micro-cognitive) sexual offender beliefs. To achieve this goal, we adapt and use the Greenwald measurement method (Greenwald et al., 2002; Greenwald \& Banaji, 1995) to test three sets of hypotheses about sexual offenders' sexual selves and their cognitive distortions. Greenwald, McGhee, and Schwartz's (1998) theory of implicit cognition provides a model of implicit stereotypes and semantic-network associations that informs the mapping of Ward's (2000) implicit theories onto testable hypotheses. We add to this a view of implicit theories and cognitive distortions, which gives consideration to sexual offenders' implicit motivations (Baumeister, 1998; Campbell \& Sedikides, 1999; Eckhardt, Barbour, \& Davison 1998; Marshall, Anderson, \& Fernandez, 1999; Payne \& Giacalone, 1990; Strong, Greene, \& Kordinak, 2002). This view is developed within a semantic and motivational account of theory. We term this the semantic-motivation hypothesis of sexual offender implicit theories.

\section{Implicit Motivation}

Cognitive distortions can be thought of as occurring at the nexus between motivation and cognition (Baumeister, 1998). Adapted to the area of offending behaviors, this is within a framework where motivational content is informative of process-level constructs such as denial, minimization, self-deception, victim-blaming, and impression management (Eckhardt et al., 1998; Marshall et al., 1999; Payne \& Giacalone, 1990). As has been explored extensively elsewhere (Mihailides, Devilly, \& Ward, 2004), the cluster of implicit motivations 
identified as important for understanding sexual offending are (i) the biological sexual motive; (ii) avoidance of disapproval; (iii) self-deceptive positivity needs; (iv) motivation for an acceptable, consistent self-concept; and (v) selfenhancement (Campbell \& Sedikides, 1999; Langton \& Marshall, 2000; Marshall et al., 1999; Strong et al., 2002; Ward, Hudson, Johnston, \& Marshall, 1997). Together, we have summarized this system as the sexual offender self-esteem hypothesis. In summary, this hypothesis states that sexual offenders are motivated to use cognitive distortions to protect self-esteem, to protect the self from perceived threat (social disapproval), to avoid cognitive dissonance, and to meet self-deceptive positivity needs.

It is important to specify that the theory here sees the mental processes involved in sexual offending as being learned and problematic, rather than biologically immutable. Implicit in this view is the hypothesis that sexual offending behavior is modifiable by appropriate kinds of psychological intervention. Also noted is that the two implicit theories not covered here ("nature of harm" and "dangerous world"; Ward \& Keenan, 1999) subsume additional motivations such as attachment- and intimacy-related motivations that need to be explored in further work.

\section{Implicit Cognition}

Implicit cognition is a theoretical view that speaks to the mental nature of tacit belief systems - that is, those things not easily measured by self-report. Crucially, implicit cognition comes with a method for testing some of its assumptions and for measuring implicit associations. Greenwald et al.'s (1998) method of measuring implicit associations is accumulating evidence at a rapid pace in a number of areas (e.g., Ashburn-Nardo, Voils, \& Monteith, 2001; Dasgupta, McGhee, Greenwald, \& Banaji, 2000; De Houwer, 2001; Greenwald \& Farnham, 2000; Milne \& Grafman, 2001; Rudman, Greenwald, Mellott, \& Schwartz, 1999; Teachman, Gregg, \& Woody, 2001). Greenwald suggests that people learn implicit associations between social targets (e.g., woman or man) and social attributes (e.g., desirable) and that these can be measured using a latency-response time paradigm.

Within this paradigm the strength of people's implicit associations is thought to affect the speed with which they respond to social stimuli. Importantly, it is a response-time paradigm that measures the difference in time between associated versus less-associated social knowledge. The core idea can be demonstrated simply as follows: a person who is asked to classify a social target (e.g., "egg") with attributes that are semantically congruent to their implicit beliefs about "egg" (e.g., "bacon") will take less time to classify "egg" with "bacon" than they would to classify "egg" with, say, "desk" (a semantically opposed/incongruent implicit association). The difference in this time of response to associated versus lessassociated knowledge is called the Implicit Association Test Effect (IAT Effect). 


\section{The Semantic-Motivation Hypothesis of Sexual Offender Implicit Theories}

The semantic-motivation hypothesis is a statement about the expected relationships between implicit motivation, cognition, and sexual offending. Within this hypothesis, there are two aspects involved in testing for the existence of an implicit association between social knowledge elements. First, there is a within-subjects aspect. This tests whether people have smaller latency response times to associated (cf. less associated) knowledge. The second component is a between-subjects test. This checks whether different types of people (e.g., sexual offenders vs. nonsexual offenders) differ in their latency response times to the same social knowledge.

For the children as sexual beings implicit theory, Ward (2000) postulates that child sexual offenders sexualize children and, implied by Ward, that sexuality is the primary motivation for this implicit theory. Using Greenwald's IAT as the measurement method, one would expect a reduced latency response time from child sexual offenders on an IAT for words about children and sexual words presented compared to incongruent words (Hypothesis 1a). And second, that compared to nonsexual offenders, the IAT effect would be larger in sexual offenders (Hypothesis 1b).

From the sexual offender self-esteem hypothesis, the motivation implied by the uncontrollability of sexuality implicit theory is that sexual offenders use this implicit theory to avoid something aversive. Namely, by seeing sexuality as uncontrollable, sexual offenders can avoid responsibility for their behavior and thus avoid cognitive dissonance and self-esteem loss (Campbell \& Sedikides, 1999; Marshall et al., 1999; Strong, et al., 2002). Alternatively, sexual offenders may use this implicit theory to avoid the loss of social approval (Strong et al., 2002). In either case, it is expected that cognitive distortions of uncontrollability of sexuality would be reflected in reduced latency response times for sexual offenders between "sexual" words and words that reflect "losingcontrol" in the congruent (cf. incongruent) condition (Hypothesis 2a), and that this IAT effect would be greater than that measured in nonsexual offenders (Hypothesis 2b).

Approach motivation is implied by the sexual entitlement implicit theory-as the power-need defined by Strong et al.'s (2002) self-deceptive positivity (to see the self as competent, effective, and powerful). Sexual entitlement cognitive distortions would be reflected in reduced latency response times for sexual offenders on "mine" words and "sexual" words presented in the congruent (cf. incongruent) condition (Hypothesis 3a), and this IAT effect should be greater than that found in nonsexual offenders (Hypothesis $3 b$ ).

The implicit associations just described for the children as sexual beings implicit theory are represented in a Social Knowledge Structure (SKS; Greenwald et al., 2002) in Fig. 1. An SKS represents the expected implicit associations between sexual offender target and attribute concepts in sexual offenders' semantic networks. 

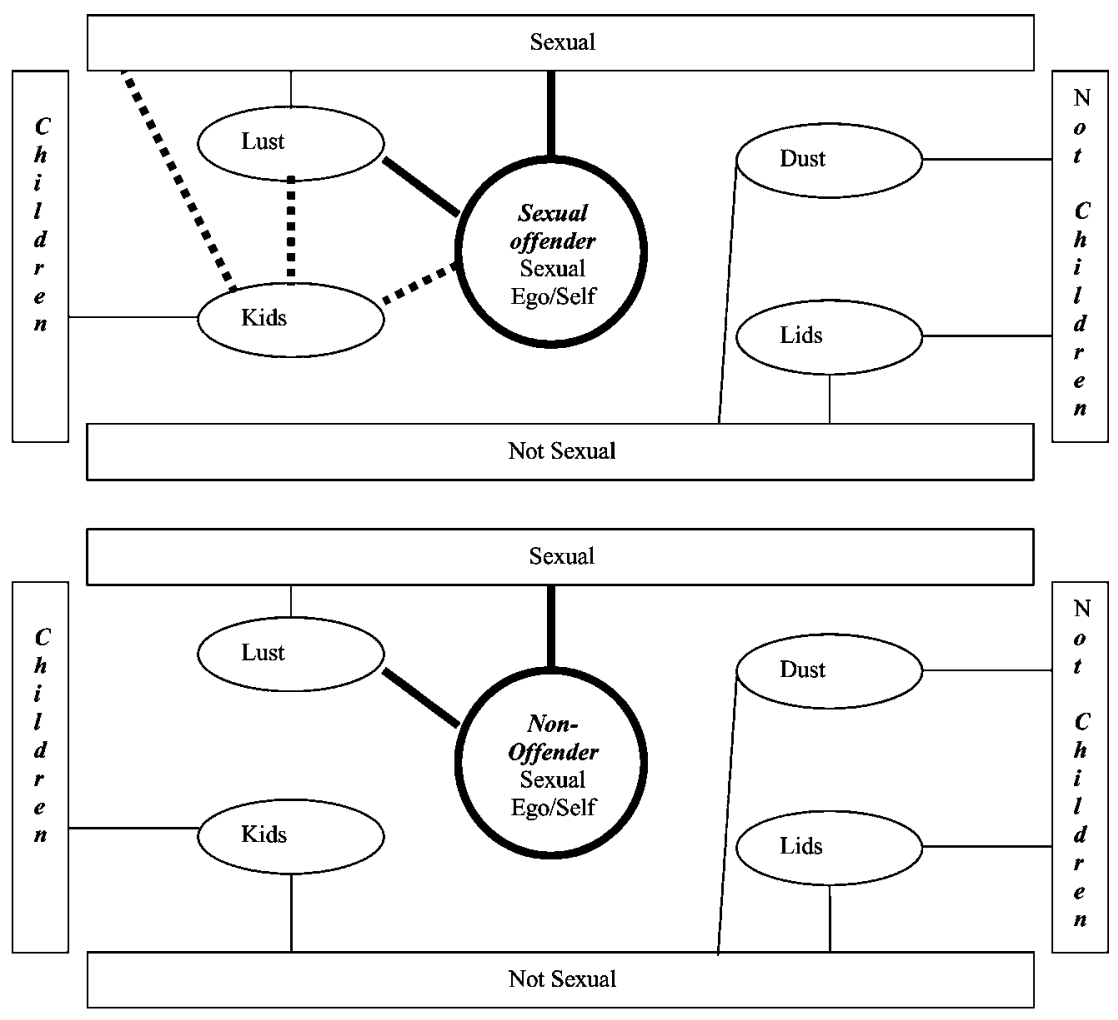

Fig. 1. Social knowledge structure of sexual offender (upper) vs. Nonsexual Offender (control) (lower) for children as sexual beings implicit theory. Dashed lines $(\cdots)$ lines indicate the semanticnetwork associations to be tested by hypothesis. Dashed lines are associations between target concepts (children) and nonvalence attributes (sexual) that are expected to be present in child sexual offenders and absent in the normal population.

\section{METHOD}

\section{Participants}

Participants in the test group comprised 25 incarcerated male child sexual offenders (mean age $=45.0, S D=11.5$ years). The three participant control groups comprised 25 incarcerated male "mainstream" offenders (mean age $=30.6$, $S D=12.0$ years) and 25 male nonoffenders (mean age $=19.9, S D=2.4$ years) and 25 female nonoffenders (mean age $=19.5, S D=3.0$ years). Mainstream offenders comprised those who evidenced an offence profile where violence was not involved, and where the participant had not committed a sexual offence of any 
kind. Non-offenders were university students from the University of Melbourne Research Participation Program.

\section{Materials}

\section{Content of Implicit Association Tasks}

For each hypothesis, there is an expected implicit association between a target concept and an accompanying congruent attribute concept (the implicitly linked nonvalence concept). Each hypothesis required four sets of experimentally manipulated stimuli: two sets of target concepts (semantically congruent and opposed) and two sets of attribute concepts (also semantically congruent and opposed).

Target concepts were five sexual offender congruent words for each implicit cognitive distortion (words about "children," "losing control," and "mine" words) and their five semantically opposed but phonetically matched words ("not-children," "not-about-control," and "not-mine" words). Attribute concepts were five congruent test words (which were "sexual" words for all three implicit theories) and five semantically opposed, but phonetically matched, words ("not-sexual").

For these four categories of words across three implicit theories, an initial 150 words for IATs were generated by three forensic researchers, with expertise in sexual offending theory, treatment, and experimental design. The five best words for each semantic category were then selected on the basis of 25 peer ratings of semantic agreement and word confusion. For the semantically opposed word categories (all the "not" words), the phonetic matching of these semantically distinct words was achieved using a combination of researcher vocabulary and an on-line song-writer's dictionary (Brett, 2002).

\section{Electronic Equipment}

The experiment was administered on an IBM Compatible computer running Win95/98 and Inquisit software (Version 1.31; Millisecond Software, 2000) for presenting target and attribute concepts of an IAT.

\section{Experiment Overview}

Each participant was administered all three IATs, and each IAT required the completion of five tasks per test: the Target Concept Discrimination (Task 1), the Associated Attribute Concept Discrimination (Task 2), Initial Combined task (Task 3), Reversed Target Concept Discrimination (Task 4), and Reversed 
Table I. Steps Involved in the Implicit Association Test (IAT) for the Children as Sexual Beings Implicit Theory

\begin{tabular}{|c|c|c|c|c|c|c|c|c|c|}
\hline Sequence & 1 & & 2 & & 3 & 4 & & 5 & \\
\hline $\begin{array}{c}\text { Task } \\
\text { Description }\end{array}$ & $\begin{array}{l}\text { Initial Target- } \\
\text { Concept } \\
\text { Discrimination }\end{array}$ & & $\begin{array}{c}\text { Associated } \\
\text { Attribute } \\
\text { Discriminatic }\end{array}$ & dion & $\begin{array}{c}\text { Initial } \\
\text { Combined Tash }\end{array}$ & $\begin{array}{l}\text { Reversed } \\
\text { Target-Concept } \\
\text { Discrimination }\end{array}$ & & $\begin{array}{c}\text { Reversed } \\
\text { Combined Tash }\end{array}$ & \\
\hline $\begin{array}{c}\text { Task } \\
\text { Instructions }\end{array}$ & $\begin{array}{l}\text { - Children } \\
\text { Not Children }\end{array}$ & & $\begin{array}{l}\text { - Sexual } \\
\text { Not Sexual }\end{array}$ & - & $\begin{array}{l}\text { - Children } \\
\text { - Sexual } \\
\text { Not Children } \\
\text { Not Sexual }\end{array}$ & $\begin{array}{l}\text { - Not Children } \\
\text { Children }\end{array}$ & & $\begin{array}{l}\text { - Not Children } \\
\text { - Sexual } \\
\text { Children } \\
\text { Not Sexual }\end{array}$ & $\bullet$ \\
\hline Sample Stimuli & $\begin{array}{l}\text { - Kids } \\
\text { Lids } \\
\text { - Children } \\
\text { Cauldron } \\
\text { - Small } \\
\text { Cauldron } \\
\text { - Underage } \\
\text { - Playful } \\
\text { - Kids } \\
\text { Rifle } \\
\text { Underline } \\
\text { Hall }\end{array}$ & $\begin{array}{l}\bullet \\
\bullet \\
\bullet\end{array}$ & $\begin{array}{l}\text { - Lust } \\
\text { Sarcasm } \\
\text { Dust } \\
\text { - Orgasm } \\
\text { Thorny } \\
\text { Direction } \\
\text { - Erection } \\
\text { - Horny } \\
\text { - Arousing } \\
\text { Horizon } \\
\text { - Lust } \\
\text { - Horny }\end{array}$ & $\begin{array}{l}\bullet \\
\bullet \\
\bullet \\
\bullet\end{array}$ & $\begin{array}{l}\text { - Kids } \\
\text { - Orgasm } \\
\text { Lids } \\
\text { Sarcasm } \\
\text { - Children } \\
\text { Horizon } \\
\text { Cauldron } \\
\text { - Arousing } \\
\text { dc. }\end{array}$ & $\begin{array}{l}\text { Kids } \\
\text { - Lids } \\
\text { Children } \\
\text { - Cauldron } \\
\text { Small } \\
\text { - Hall } \\
\text { Underline } \\
\text { Playful } \\
\text { Kids }\end{array}$ & & $\begin{array}{l}\text { - Lids } \\
\text { - Orgasm } \\
\text { Kids } \\
\text { Sarcasm } \\
\text { - Cauldron } \\
\text { Horizon } \\
\text { Children } \\
\text { - Arousing } \\
\text { etc. }\end{array}$ & $\bullet$ \\
\hline
\end{tabular}

Combined task (Task 5). Thus, all participants completed 15 sets of presentations ( 3 tests $\times 5$ individual tasks). The IAT Effect is measured by statistically comparing the latency response times of Task 3 with those of Task 5 (Greenwald et al., 1998). Table I summarizes the sequence of events involved in measuring an IAT effect for the children as sexual beings implicit theory. The details of all five tasks are further elaborated in the Procedure section.

\section{Procedure}

Initial contact with the offender groups was obtained following ethical clearance and advertisements within correctional facilities. Participants who responded were shown to a desk and seated $0.6 \mathrm{~m}$ from a standard IBM-PC. Participants were reminded that they could cease participation at any point in the process and following completion of the study, "experimental" debriefing was made available to all participants. For the two nonoffender groups, initial contact was achieved by way of an advertisement, auspiced by the Ethics Committee at the University of Melbourne.

\section{Counterbalancing Measures}

There are two ways of extracting data as an IAT effect: Task 3 can be presented with either the Compatible condition first or the Incompatible condition first. Conversely where Task 3 is Compatible first, Task 5 must be Incompatible second, and where Task 3 is Incompatible first, Task 5 must be Compatible second. 
The IAT is known to produce a procedural artefact whereby IAT magnitudes differ depending on how Task 3 is presented (Compatible or Incompatible first). Therefore, task-compatibility order was counterbalanced so that half the participants completed Task 3 with the Incompatible condition first, and half completed Task 3 with the Compatible condition first (Greenwald et al., 1998).

Handedness was also counterbalanced, where half the participants completed the congruent attribute concepts in Task 2 with their right hand, and then with left hand in Task 4 . The second half of participants completed the congruent concepts in Task 2 with their left hand, and then with their right hand in Task 4. Because there are three experiments (one for each implicit theory being tested), a third level of counterbalancing required that the order of presentation of each IAT be rotated.

\section{Trial Blocks}

All experimental tasks were administered in trial blocks. There were five trial blocks per experiment, where one trial block corresponded to one experimental task (refer Table I). A trial block was initiated with screen instructions to the participant that described the nature of the pending target concepts and attribute concepts (e.g., experiment 1, block 1: children vs. not-children words). Each trial block also came with screen instructions that linked a target or attribute concept to the left or right hand. Reminder labels were positioned on the screen throughout the course of the experiment (e.g., on the left side of the screen: "Left-Shift for children or sexual" and on the right side of the screen "Right-Shift for not-children or not-sexual").

For each experiment, trial block 1 was a target concept discrimination task (e.g., children vs. not-children words for Hypothesis 1), where target words were blue on a black screen. Trial block 2 was an attribute concept discrimination (e.g., sexual vs. not-sexual words for Hypothesis 1), where attribute words were green on the screen. Trial block 3 was a combined task. In the combined task, individual words were intermittently target concepts, followed by attribute concepts. At all times, the computer screen showed the hand assignments for both target concepts and attribute concepts. Trial block 4 reversed the hand assignment of target concepts (e.g., if sexual concepts were assigned to the left hand in trial block 2, then in block 4 they were assigned to the right hand). Trial block 5 was the second combined task, but with target concepts assigned to the hand as per block 4 (i.e., the reverse hand assignments of blocks 2; see Fig. 2).

For example, for the children as sexual beings implicit cognitive distortion, the Compatible condition presented congruent target concepts (children) with congruent attribute concepts (sexual) assigned to the same hand on the computer screen. Likewise, semantically opposed, phonetically similar, target concepts (not-children) were presented with opposed attribute concepts (not-sexual) on 


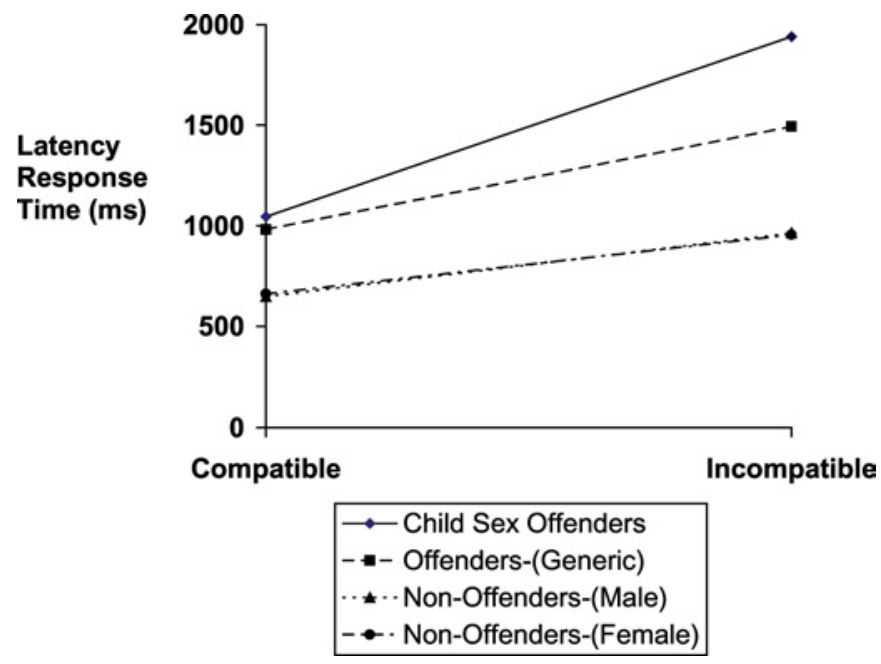

Fig. 2. IAT effects of criterion groups for the "Sexual Entitlement-Bias" word sets.

the other hand. For the Incompatible condition, congruent target concepts (children) were presented with opposed attribute concepts (not-sexual) on the same hand, and opposed target concepts (not-children) were presented with congruent attribute concepts (sexual) on the other hand. The Compatible first and Incompatible first conditions were counterbalanced over trial blocks 3; and conversely, the accompanying Incompatible second and Compatible second conditions were counterbalanced over trial block 5. A computerized random selection algorithm was utilized to present words in random order.

\section{RESULTS}

A visual inspection of preaggregated univariate distributions revealed curves that were best bounded by responses that fell between $300 \mathrm{~ms}(0.5 \%<300 \mathrm{~ms})$ and $6,000 \mathrm{~ms}(0.8 \%>6,000 \mathrm{~ms})$ response time range. Responses that fell outside this range were recoded to lie on the $300-6,000$ ms boundary. No influential multivariate outliers were detected.

The means and standard deviations of the latency response times for the three experiments, the four participant groups in the corresponding experimental conditions (Compatible, Incompatible), and across the three experiments are summarized in Table II. 
Table II. Means, Standard Deviations of Latency Response Times in Milliseconds for Each Implicit Theory by Participant Group and IAT Experimental Conditions for the Children as Sexual Beings Experiment

\begin{tabular}{lllrrr}
\hline IAT experiment & \multicolumn{1}{c}{ Participant group } & IAT condition & $M^{a}$ & Mdn & \multicolumn{1}{c}{$S D$} \\
\hline $\begin{array}{l}\text { Children as sexual } \\
\text { beings }\end{array}$ & Offenders (child sexual & Compatible & 1,046 & 922 & 546 \\
& offenders) & Incompatible & 1,941 & 1,596 & 1,004 \\
& Offenders (mainstream) & Compatible & 981 & 909 & 302 \\
& & Incompatible & 1,494 & 1,476 & 320 \\
& Nonoffenders (male) & Compatible & 647 & 637 & 116 \\
& Nonoffenders (female) & Incompatible & 964 & 960 & 224 \\
& & Compatible & 661 & 618 & 149 \\
& Offempatible & 955 & 952 & 226 \\
Uncontrollability & offenders) & Compatible & 1,222 & 1,148 & 498 \\
of sexuality & & Incompatible & 2,179 & 1,973 & 815 \\
& & Compatible & 1,335 & 1,200 & 609 \\
& Offenders (mainstream) & Incompatible & 1,951 & 1,891 & 516 \\
& Nonoffenders (male) & Compatible & 714 & 656 & 166 \\
& & Incompatible & 1,112 & 1,032 & 244 \\
& Nonoffenders (female) & Compatible & 695 & 645 & 195 \\
& & Incompatible & 1,128 & 1,154 & 257 \\
& Offenders (child sexual & Compatible & 1,151 & 1,101 & 437 \\
& offenders) & Incompatible & 1,756 & 1,581 & 560 \\
Sexual entitlement & & Compatible & 1,111 & 1,064 & 381 \\
bias & Offenders (mainstream) & Incompatible & 1,586 & 1,504 & 487 \\
& & Compatible & 686 & 647 & 163 \\
& Nonoffenders (male) & Incompatible & 986 & 979 & 204 \\
& & Compatible & 711 & 667 & 188 \\
& Nonoffenders (female) & Incompatible & 994 & 939 & 224 \\
\hline & & & & &
\end{tabular}

Note. $N=100$.

${ }^{a} n=2$.

\section{Overview of Analyses}

Each hypothesis was tested within a 2 (IAT Condition: Compatible, Incompatible) $\times 4$ (Criterion Group: Offender (Child Sexual Offender), Offender (Mainstream), Nonoffender (Male), Nonoffender (Female)) mixed design multivariate, repeated measures analysis of variance (ANOVA) experimental model, where the dependent variables were participant latency response times. Male and female nonoffender results were not significantly different $(p<.05)$ from each other, but were kept as separate groups to ensure that ANOVA cell sizes remained equal $(n=25)$ so that the analyses remained robust to violations of parametric assumptions (Francis, 1998). The within-subjects independent variable was IAT Condition and the between-group independent variable was participant grouping. 


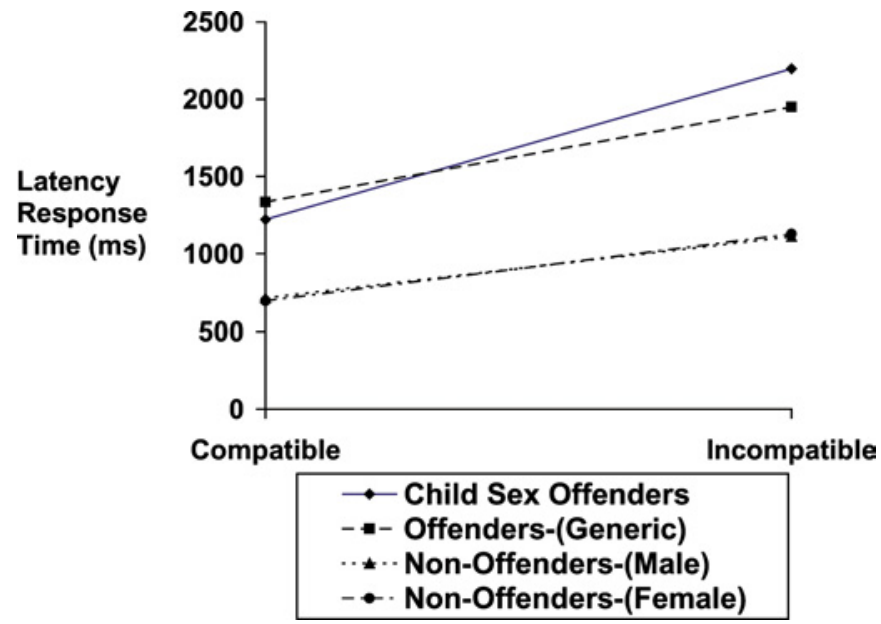

Fig. 3. IAT Effects of criterion groups for the "Children as Sexual Beings" word sets.

\section{Experimental Analyses}

\section{Hypotheses 1A and 1B: Children as Sexual Beings}

The multivariate interaction of IAT effect with condition was significant; IAT Condition $\times$ Criterion Group, Wilks's $\Lambda=0.75, F(3,96)=10.49, p<.001$. The univariate interaction- $F(3,96)=10.49, p<.001, \eta^{2}=0.25$-is plotted in Fig. 3.

A separate one-way ANOVA was conducted on the sexual offender criterion group's latency response times to test the expectation that an IAT effect exists in this group, for the experimental stimuli used in the Compatible versus Incompatible conditions. Consistent with expectation, sexual offenders took significantly longer to classify "children" and "sexual" concepts (and their bipolar opposed concepts) in the Incompatible experimental condition than it did for them to classify the same concepts in the Compatible condition; $F(1,24)=34.69, p<.001$, $\eta^{2}=0.59$. Another way of stating this is to say that it took longer for sexual offenders to classify words "about-children" with "not-sexual" concepts (Incompatible) or words "not-about-children" with "sexual" concepts (Incompatible) than it did for this same group to classify words "about-children" with "sexual" concepts (Compatible) or words "not-about-children" with "not-sexual" concepts (Compatible).

The normal process of interpreting two-way interactions by splitting the data file into Compatible and Incompatible components and then performing separate 
one-way ANOVAs (on participant Criterion Group) would not yield the significance test required. The conventional analysis would yield four separate statements about each criterion group's performance in the Compatible and then Incompatible conditions in isolation. Alternatively, splitting the data file by participant group would have yielded separate statements about an IAT effect for each participant group in isolation. Neither of these analyses compares the relative IAT effect between groups, where the relative IAT effect is concerned with the relative slopes of each criterion group across the Compatible versus Incompatible conditions. Instead, it was necessary to firstly compute the change scores in latency response times (named as $\Delta v$ ) for each criterion group as follows:

$$
\begin{aligned}
\Delta v= & \{\text { latency response time (Incompatible) } \\
& - \text { latency response time (Compatible) }\} .
\end{aligned}
$$

The relative change in latency response times could then be compared across criterion groups by conducting a one-way ANOVA, with $\Delta v$ scores as the dependent variable and Criterion Group acting as the independent variable. Consistent with our hypothesis, planned comparisons revealed that the relative IAT effect (the comparison of slopes of the lines in Fig. 3) for sexual offenders was significantly greater than the analogous IAT effect for male offenders (mainstream), $t(96)=3.15$, $p<.01$; nonoffenders (male), $t(96)=4.76, p<.001$; and for nonoffenders (female), $t(96)=4.95, p<.001$.

\section{Hypotheses $2 A$ and 2B: Controllability of Sexuality}

As with Hypotheses 1A and 1B, a significant two-way multivariate interaction between IAT Condition and Criterion Group was found; Wilks's $\Lambda=0.79$, $F(3,96)=8.66, p<.001)$. The two-way univariate interaction, $F(3,96)=8.66$, $p<.001, \eta^{2}=0.21$, is plotted in Fig. 4. The profile of results for "uncontrollability of sexuality" was isomorphic with those of the "children as sexual beings" hypothesis. A separate one-way ANOVA conducted on the sexual offender criterion group's latency response times in the Compatible versus Incompatible conditions revealed that sexual offenders took significantly longer to classify concepts in the Incompatible experimental condition than it did for them to classify the same concepts in the Compatible condition, $F(1,24)=47.51, p<.001, \eta^{2}=0.66$ ). That is, it took longer for sexual offenders to classify "sexual" concepts with "not-about-control" concepts (Incompatible) or words that were "not-sexual" with "losing-control" concepts (Incompatible) than it did for this same group to classify either "losing-control" concepts with "sexual" concepts (Compatible) or words "not-about-control" with "not-sexual" concepts (Compatible). 


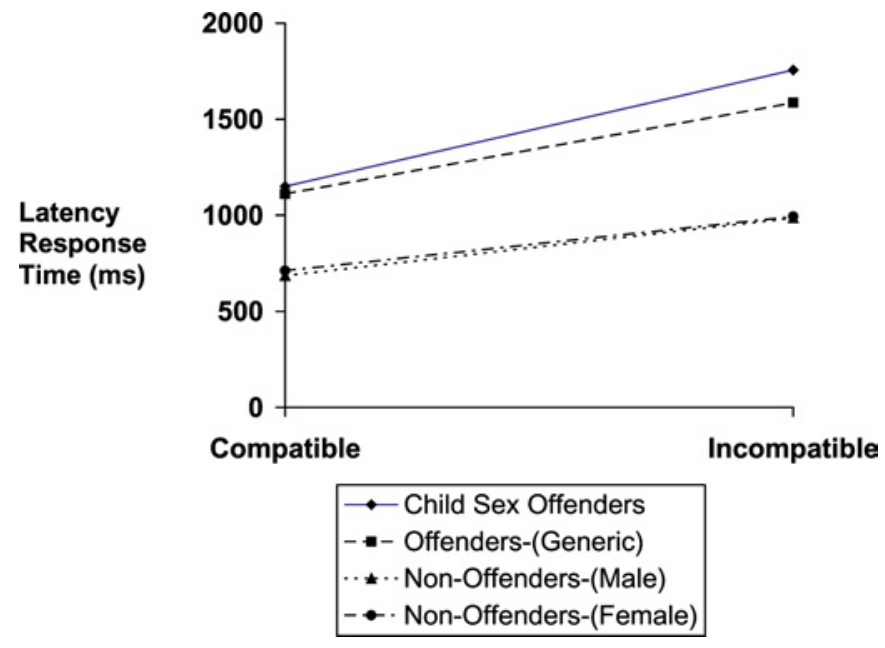

Fig. 4. IAT effects of criterion groups for the "Uncontrollability of Sexuality" word sets.

As was the case with the children as sexual beings analyses, the second part of the second hypothesis was concerned with the relative size of the sexual offenders' IAT effect, when it is compared to any IAT effect in the three control criterion groups. Therefore, this analysis was concerned with the relative change in latency response time scores ( $\Delta v$ scores) between the two experimental conditions, in the four criterion groups. $\Delta v$ scores were calculated in the same way as they were in the previous analyses and then used in a one-way ANOVA model, with Criterion Group as the independent variable. As hypothesized, the relative IAT effect for sexual offenders was significantly greater than the analogous IAT effect for male offenders (mainstream), $t(96)=2.78, p<.01$; for nonoffenders (male), $t(96)=4.55, p<.001$; and for nonoffenders (female), $t(96)=4.26, p<.001$.

\section{Hypotheses 3A and 3B: Sexual Entitlement Bias}

As above, a significant two-way multivariate interaction between IAT Condition and Criterion Group, Wilks's $\Lambda=0.81, F(3,96)=7.58, p<.001$, was found for the sexual entitlement bias distortion. The two-way univariate interaction between IAT Condition and criterion group, $F(3,96)=7.58, p<.001$, $\eta^{2}=0.19$, is plotted in Fig. 4 .

The IAT effect for the sexual offenders criterion group was again quantified by conducting a separate one-way ANOVA that compared child sexual offenders' latency response times in the Compatible versus Incompatible experimental conditions. Consistent with expectation, sexual offenders took significantly longer to 
classify experimental concepts in the Incompatible experimental condition than they did for the same concepts in the Compatible condition, $F(1,24)=46.45$, $p<.001, \eta^{2}=0.66$. Another way of stating this is to say that it took longer for sexual offenders to classify "mine" words with "not-sexual" concepts (Incompatible) or "not-mine" words with "sexual" concepts (Incompatible) than it did for them to classify "mine" words with "sexual" concepts (Compatible) or "not-mine" words with "not-sexual" concepts (Compatible).

The relative IAT effect for sexual offenders was not significantly greater than the analogous IAT effect for offenders (mainstream), $t(96)=1.65, p=.10$; however, the trends in means were in the predicted direction and approached significance. It is likely that a larger sample size would have increased the power of the experiment to achieve a statistically significant result. The relative IAT effect for sexual offenders was, however, significantly greater than the IAT effect for nonoffenders (male), $t(96)=3.88, p<.01$, and for nonoffenders (female), $t(96)=4.09, p<.001$.

\section{Effect Sizes}

For each hypothesis, a follow-up calculation was conducted to quantify the interaction effect sizes (Cohen's $d$ ) for the mean latency response time change between Compatible and Incompatible conditions or $M(\Delta v)$ of the relative IAT effect between sexual offenders and each of the three comparison groups. The computation of $d$ was as follows:

$$
d=\left\{M_{1}(\Delta v)-M_{2}(\Delta v)\right\} / s_{(12)}
$$

where $d=$ effect size; $M_{1}(\Delta v)=$ mean latency response time change between Compatible and Incompatible conditions of the sexual offender criterion group; $M_{2}$ $(\Delta v)=$ mean latency response time change between Compatible and Incompatible conditions of the comparison group; and $s_{(12)}=$ pooled standard deviation (over both groups and both experimental conditions).

The interaction effect sizes of the relative IAT effect of sexual offenders compared to the three criterion groups are summarized in Table III. As can be seen, the differences between sex offenders and generic offenders display moderate to large effect sizes where significant, and the difference between sex offenders and male and female nonoffenders were all of a large magnitude.

A series of subsidiary analyses confirmed the immunity of IAT in the current experiment to handedness effects, to differences in criterion groups' response times to IAT stimuli, and to age effects (in the control groups). In summary, being left or right handed made no difference to the effect, being generally fast or slow to respond also made no difference to the IAT effect (which measures relative differences). Likewise participant age differences (in this study) made 
Table III. Interaction Effect Sizes $(d)$ for the Relative Mean Change $\{m(\Delta v)\}$ of the Relative IAT Effect Contrasting Sexual Offenders With Each of the Three Comparison Groups

\begin{tabular}{lccc}
\hline & \multicolumn{3}{c}{ Interaction effect size $(d)$ for IAT component } \\
\cline { 2 - 4 } Hypothesis & Offenders (mainstream) & Nonoffenders (male) & Nonoffenders (female) \\
\hline CSBeings & 0.63 & 0.92 & 0.97 \\
COfSex & 0.58 & 0.97 & 0.90 \\
SEntitle & $0.35^{a}$ & 0.84 & 0.89 \\
\hline
\end{tabular}

Note . CSBeings $=$ Children as sexual beings hypothesis; COfSex $=$ Controllability of sexuality hypothesis; SEntitle = Sexual entitlement-bias hypothesis.

${ }^{a}$ Mean difference in this cell was not significant.

no difference to the IAT effect (see Hummert, Garstka, O'Brien, Greenwald, \& Mellott, 2002).

\section{DISCUSSION}

This research aimed to test for the existence of implicit associations and motivations that are hypothesized to underlie sexual offenders' cognitive distortions. The results have provided the first evidence for the existence of stronger implicit associations in sexual offenders compared to nonsexual offenders on three of Ward's (2000) sexual offender implicit theories. Evidence of stronger implicit associations were found for the children as sexual beings, the uncontrollability of sexuality, and the sexual entitlement implicit theory, compared to nonoffenders. Relative to offenders (mainstream), two of the three associations were found in sexual offenders (children as sexual beings and uncontrollability of sexuality, but not for the sexual entitlement bias).

The children as sexual beings implicit theory assumes that sexual offenders' distorted beliefs about children's sexuality would be implicitly motivated by human sexuality. This research found evidence that sex offenders infuse sexuality onto social targets (children).

The implicit motivation of uncontrollability of sexuality assumes that sexual offenders use this cognitive distortion to avoid disapproval, or to conserve and/or enhance self-concept and/or self-esteem (Campbell \& Sedikides, 1999; Laws, Hudson, \& Ward, 2000; Marshall et al., 1999; Strong et al., 2002). It was found that there are stronger implicit semantic associations between sexual concepts and concepts that reflected losing control in sexual offenders versus the other groups. Further experimental work is required to more carefully explore the relationship between implicit motivation and cognitive distortions about "uncontrollability of sexuality." One suggestion would be to experimentally manipulate social approvaldisapproval (and/or self-concept/self-esteem) and to then measure activity on the "uncontrollability of sexuality" implicit distortion. 
The sexual entitlement implicit theory assumes that the underlying motivation for sexual offending includes an egocentric leaning towards self-deceptive positivity (Strong et al., 2002). It was expected that sexual entitlement cognitive distortions would be reflected in the implicit semantic associations between firstperson concepts ("mine" concepts) and sexual concepts. Partial support was found for this position in that the relative IAT effect of sexual offenders on this construct was significantly greater than that for male and female university students, but it was not significantly greater than mainstream offenders (nonsexual).

In regards to the nonsignificant difference between the two offender groups, we hypothesize that offenders may hold distorted views that have a foundation in implicit egocentrism and that this effect generalizes to sexuality as well as to other areas. It could be argued that offenders' thinking in general involves an overinvested self-entitlement. It is arguable that by excessively entitling the self, offenders can deny responsibility for the effects of their choices on others. Distorted views about entitlements (i.e., "I am entitled") may offset a sense of personal agency for harming. Where offenders feel entitled may be the point where they deny or minimize victims' rights, thereby minimizing their perceived responsibility for caused harm.

Alternatively, it is possible that the operationalization pathway of the sexual entitlement bias was not reflective of a sexual entitlement bias per se, but was instead reflective of another construct that differs in university students compared to offending populations. The target concepts were "mine," "not-mine," "sexual," and "not-sexual." Within this framework, a "mine-sexual" implicit association may reflect a more generalized construct to do with the sexual self, rather than the entitled sexual self.

The average age of university students was under 20, compared to both offender groups whose average age was about 15 years older. It is, therefore, possible to argue the observed differences between offenders and nonoffenders on the mine-sexual IAT from a developmental framework. This might be where, for example, the sexual self implicit association is expected to strengthen with age in all sexually active people. Although this makes intuitive sense, it remains to be tested within an empirical model. A control nonoffender group that was age matched would clarify this ambiguous finding.

Beyond individual implicit theories, this work has the potential to be informative of the relationship between implicit semantic constructs, cognitive distortions, and sexual offending behavior. Sexual offender implicit theories can inform the cognition-behavior relationship, even though sexual offending behavior is ultimately the subject of aetiological models of sexual offending (for a review, see Laws et al., 2000). Aetiological models require consideration of the temporal dimension of sexual offending and they thus go beyond the scope of this work. Nonetheless, several points can be made regarding sexual offending behavior.

Ward (2000) and Ward and Keenan (1999) predicted a constellation of semantic organizational forms and contents expected to exist in association with 
sexual offender implicit theories and in association with cognitive distortions and sexual offending behavior. The children as sexual beings, uncontrollability of sexuality, and sexual entitlement implicit theories are summary labels for three of these basic semantic forms.

The results of this study support the claims made by Ward (2000) and Ward and Keenan (1999) in that the predicted differences in the implicit associations underlying sexual offender cognitive systems were evident when the comparison groups were mainstream offenders or male and female nonoffenders. Within this framework, sexual offender implicit distortions represent an important adjunctive component for aetiological models that make predictions regarding sexual offending behavior.

However, we urge caution when abstracting causation for behavior. The question of cause and effect remains open, because although this work did experimentally manipulate the presentation of content from implicit theories, it did not explore how manipulation of content influences the behavioral manifestations of implicit cognitive distortions in criterion groups. Therefore, the exact role that cognitive distortions play in offending behavior remains untested.

Sexual offender implicit cognitive distortions (Ward, 2000; Ward \& Keenan, 1999) are informative of the intermediate space between macro-motivational and micro-cognitive accounts of cognitive distortions and sexual offending. The empirical results of this work provided evidence that was consistent with the assumptions of a belief-desire view (Ward, 2000) of sexual offending. Results were also supportive of the micro-cognitive expectations that underpins the semantic-network level of analysis and consistent with the tenets of implicit cognition as defined and tested by Greenwald et al. (1998, 2002).

Future work should explore further implications for the semantic-motivation hypothesis. In particular, this hypothesis can be used to formulate theoretical predictions about the sexual-self in the context of treatment options and in regards to the changeability of cognitive distortions. Importantly, within the Greenwald et al. (1998) paradigm, these predictions become testable-an essential step for understanding how to devise interventions so as to prevent the harm caused by sexual offences.

\section{ACKNOWLDGMENTS}

The authors thank the participants who donated their time to take part in this research.

\section{REFERENCES}

Ashburn-Nardo, L., Voils, C. I., \& Monteith, M. J. (2001). Implicit associations as the seeds of intergroup bias: How easily do they take root? Journal of Personality and Social Psychology, 81, 789-799. 
Baumeister, R. F. (1998). The self. In D. T. Gilbert, S. T. Fiske, \& G. Lindzey (Eds.), The handbook of social psychology (4th ed.) (pp. 680-740). Boston: McGraw-Hill.

Brett, M. (2002). Lexicate Online Dictionary List Retrieved from http://www.lexicate.com

Campbell, W. K., \& Sedikides, C. (1999). Self-threat magnifies the self-serving bias: A meta-analytic integration. Review of General Psychology, 31, 23-43.

Dasgupta, N., McGhee, D. E., Greenwald, A. G., \& Banaji, M. R. (2000). Automatic preference for White Americans: Eliminating the familiarity explanation. Journal of Experimental Social Psychology, 36, 316-328.

De Houwer, J. (2001). A structural and process analysis of the Implicit Association Test. Journal of Experimental Social Psychology, 37, 443-451.

Eckhardt, C. H., Barbour, K. A., \& Davison, G. C. (1998). Articulated thoughts of maritally violent and nonviolent men during anger arousal. Journal of Counselling and Clinical Psychology, 66, 259-269.

Francis, G. (1998). Multivariate analysis of variance. Melbourne: Swinburne University of Technology.

Greenwald, A. G., \& Banaji, M. R. (1995). Implicit social cognition: Attitudes, self-esteem, and stereotypes. Psychological Review, 102, 4-27.

Greenwald, A. G., Banaji, M. R., Rudman, L. A., Farnham, S. D., Nosek, B. A., \& Mellott, D. S. (2002). A unified theory of implicit attitudes, stereotypes, self-esteem, and self-concept. Psychological Review, 109, 3-25.

Greenwald, A. G., \& Farnham, S. D. (2000). Using the implicit association test to measure self-esteem and self-concept. Journal of Personality and Social Psychology, 79, 1022-1037.

Greenwald, A. G., McGhee, D. E., \& Schwartz, J. L. K. (1998). Measuring individual differences in implicit cognition: The implicit association test. Journal of Personality and Social Psychology, $74,1464-1480$.

Hummert, M. L., Garstka, T. A., O’Brien, L. T., Greenwald, A. G., \& Mellott, D. S. (2002). Using the implicit association test to measure age differences in implicit social cognition. Psychology and Aging, 17, 482-495.

Langton, C. M., \& Marshall, W. L. (2000). The role of cognitive distortions in relapse prevention programs. In D. R. Laws, S. M. Hudson, \& T. Ward (Eds.), Remaking relapse prevention with sexual offenders (pp. 167-186). Thousand Oaks, CA: Sage.

Laws, D. R., Hudson, S. M., \& Ward, T. (2000). Remaking relapse prevention with sex offenders. Thousand Oaks, CA: Sage.

Marshall, W. L., Anderson, D., \& Fernandez, Y. (1999). Cognitive behavioural treatment of sexual offenders. Brisbane, Australia: Wiley.

Mihailides, S. P., Devilly, G. J., \& Ward, T. (2004). Meaning and motivational systems in sexual offenders' cognitive distortions. Manuscript in preparation.

Millisecond Software. (2000). Inquisit [Computer software]. Seattle, WA: Author.

Milne, E., \& Grafman, J. (2001). Vetromedial prefrontal cortex lesions in humans eliminate implicit gender stereotyping. Journal of Neuroscience, 21, 1-6.

Payne, S. L., \& Giacalone, R. A. (1990). Social psychological approaches to the perception of ethical dilemmas. Human Relations, 43, 649-665.

Rudman, L. A., Greenwald, A. G., Mellott, D. S., \& Schwartz, J. L. K. (1999). Measuring the automatic components of prejudice: Flexibility and generality of the implicit association test. Social Cognition, 17, 437-465.

Strong, D. R., Greene, R. L., \& Kordinak, S. T. (2002). Taxometric analysis of impression management and self-deception in college student and personnel evaluation settings. Journal of Personality Assessment, 78, 161-175.

Teachman, B. A., Gregg, A. P., \& Woody, S. R. (2001). Implicit associations for fear-relevant stimuli among individuals with snake and spider fears. Journal of Abnormal Psychology, 110, 226-235.

Ward, T. (2000). Sexual offenders' cognitive distortions as implicit theories. Aggression and Violent Behavior, 5, 491-507.

Ward, T., Hudson, S. M., Johnston, L., \& Marshall, W. L. (1997). Cognitive distortions in sex offenders: An integrative review. Clinical Psychology Review, 17, 479-507.

Ward, T., \& Keenan, T. (1999). Child molesters' implicit theories. Journal of Interpersonal Violence, $14,821-838$. 